\title{
OPEN Community structure of fungal pathogens causing spikelet rot disease of naked oat from different ecological regions of China
}

\begin{abstract}
Longlong Liu ${ }^{\bowtie}$, Mingchuan Ma, Zhang Liu, Lijun Zhang \& Jianping Zhou
Spikelet rot disease (SRD) is an emerging disease of the grain surface of naked oat in China that affects both grain yield and quality. The typical symptom is discoloration from the black structures of the causal fungi. Here, we investigated the fungal communities on the grain surfaces of cultivar Bayou 13 grown in ten ecological oat-producing regions of China, to identify the main pathogens of naked oat SRD. Our results showed that the growth of Alternaria spp. and Davidiella spp. exhibited a competitive relationship and was mainly affected by the elevations of all 10 ecological regions. The dominant pathogens were Davidiella spp. in Shannan Prefecture in Tibet and Haidong Prefecture in Qinghai Province and Alternaria spp. in the other eight regions. The ratios of black pathogens of interest to all pathogens in Shannan Prefecture and Haidong Prefecture were significantly lower than those of the other eight regions, thus indicating that SRD mainly occurred in regions below $2000 \mathrm{~m}$ (elevation). We isolated black fungal pathogens from grain surfaces and deduced that they were Alternaria spp. by sequence comparison. The blackened appearance of the grain surfaces was more evident under spray inoculation with a spore suspension of Alternaria than under the control in greenhouse experiments. The recovered pathogen was the same as the pathogen used for inoculation. We thus concluded that Alternaria alone causes naked oat SRD and mainly infects naked oat in regions below 2000 m, which provides a basis for the recognition and management of SRD of naked oat.
\end{abstract}

Oat (Avena sativa) is one of the most important cereal crops in the world and is cultured in all agricultural regions of the world with a moderate climate ${ }^{1}$. The hexaploid cultivated species $A$. sativa is represented by both hulled (A. sativa subsp. sativa L.) and naked forms (A. sativa subsp. nudisativa (Husnot.) Rod. et Sold. $)^{2}$, which are believed to have originated in $\mathrm{China}^{3}$. The yield and composition of nutritional and functional active ingredients were higher in naked oat than in hulled oat ${ }^{4,5}$. Naked oat is the main cultivated oat species in China, accounting for $92 \%$ of the total area planted in oat $\left(106.7 \mathrm{hm}^{2} \text { of } 120.0 \mathrm{hm}^{2}\right)^{6}$. Naked oat is mainly distributed in arid and cold regions, including Inner Mongolia, Yunnan Province, Gansu Province, Sichuan Province, Hebei Province, Shanxi Province, Qinghai Province, Jilin Province, and Tibet ${ }^{7}$. In these regions, rainfall is scarce and mostly concentrated from July to September. The occurrence of continuous rainfall during the harvest season leads to high moisture and warm temperatures being important factors in the spread of plant diseases ${ }^{8}$. In this period, many fungi on glumes and panicles of weakened plants or moribund tissues of cereal crops result in grain discoloration ${ }^{9}$. Extensive occurrence of spikelet rot disease (SRD, Supplementary Figure S1) on oat grains in fields is a result of rainfall just before harvest and is a regularly observed phenomenon ${ }^{10}$.

SRD of naked oat is characterized by black fungal discoloration, especially on the surface of the kernels as well as beneath the pericarp of the grain ears ${ }^{11}$. This discoloration is mainly considered a blemish of the grain but not a factor affecting quality ${ }^{10}$. This disease has generally received comparatively little attention and is considered a minor disease that does not warrant specific control measures ${ }^{10}$ when compared with oat diseases such as rusts, blights, smuts, spots, and culm and root rots ${ }^{1,12-14}$. Recently, the most general usage of naked oat has been for livestock feed, but oat consumption as a human food has recently increased, perhaps due to the reported health benefits arising from the nutritional value of the grains ${ }^{14}$. However, fungal infection of grains in the field may result in yield nutritive value reduction and the production of toxins that are harmful to humans and animals ${ }^{10,15,16}$. Thus, a high grain quality is of great significance to the safe production of naked oat products. 


\begin{tabular}{|l|c|l|l|}
\hline Ecological region & Valid sequences & High-quality sequences & High-quality sequences/valid sequences (\%) \\
\hline Kelan County, Shanxi Province & 158,447 & 157,375 & 99.32 \\
\hline Dingxi City, Gansu Province & 200,080 & 199,194 & 99.56 \\
\hline Datong City, Shanxi Province & 125,628 & 125,155 & 99.62 \\
\hline Chifeng City, Inner Mongolia & 185,197 & 182,857 & 98.74 \\
\hline Jining City, Inner Mongolia & 133,994 & 133,281 & 99.47 \\
\hline Hinggan League, Inner Mongolia & 120,721 & 119,073 & 98.63 \\
\hline Zhangjiakou City, Hebei Province & 146,646 & 146,049 & 99.59 \\
\hline Baicheng City, Jilin Province & 153,187 & 151,395 & 98.83 \\
\hline Shannan Prefecture, Tibet & 114,171 & 113,867 & 99.73 \\
\hline Haidong Prefecture, Qinghai Province & 120,714 & 120,231 & 99.60 \\
\hline Total & $1,458,785$ & $1,448,477$ & 99.29 \\
\hline
\end{tabular}

Table 1. Valid and high-quality sequences obtained from metagenomic sequencing of fungal pathogens on the surfaces of Bayou 13 grains from 10 ecological regions.

Most studies have focused on rice SRD, and one of its features is that it is not associated with one but four different pathogens ${ }^{17-21}$. Previous reports have shown that many fungi, including members of the genera Alternaria and Fusarium, are associated with grain contamination of oat, wheat and barley ${ }^{10,15,22-26}$. Species of the genera Alternaria and Fusarium are plant pathogens and are commonly found as surface contaminants on grains, in soil and on dead or dying plant tissues ${ }^{10}$. With sufficient surface moisture, the fungal spores present on the kernels can germinate and grow. With sufficient fungal growth, the husk can become discolored. However, Fusarium spp. were not observed on normal and discolored grains of naked oat in China, while more Alternaria spp. were isolated from discolored grains than from normal grains ${ }^{27}$. Currently, there are no systematic reports on SRD on naked oat, but it is considered an increasingly important disease of naked oat in China. Such a lack of knowledge hampers the development of suitable disease risk forecasts and control measures.

The species abundance and composition of the microbiota are important factors in determining the quality of the grain ${ }^{15}$. Throughout the growing season, weather conditions such as temperature and humidity influence the distribution of the infecting fungal species and lead to geographical variation in the species distribution ${ }^{28-31}$. As the main cultivar of naked oat in China, Bayou 13 is planted in different ecological regions, including Tibet, Shanxi Province, Gansu Province, Inner Mongolia, Qinghai Province and Hebei Province. Therefore, in this study, we investigated fungal pathogens found on the surfaces of grains produced in these regions associated with typical SRD symptoms, identified the associated black pathogens, and carried out greenhouse infection experiments to determine the main pathogen and pathogen distribution for this disease.

\section{Results}

Metagenomic sequence characteristics of fungal pathogens on grains from different ecological regions. Metagenomic sequencing of the fungal communities on the grain surfaces of Bayou 13 obtained from 10 ecological regions during the harvest season yielded 1,458,785 valid sequences, with $99.29 \%$ $(1,448,477)$ being high-quality sequences. The proportion of high-quality sequences was more than $97 \%$ for all regions. The samples from Shannan Prefecture produced the fewest valid and high-quality sequences $(114,171$ and 113,867, respectively). The samples from Dingxi City in Gansu yielded the most valid and high-quality sequences (200,080 and 199,194, respectively) (Table 1). The sequences had lengths ranging from 173 to $283 \mathrm{bp}$, with 480,675 (33.18\%) sequences having a length of $260 \mathrm{bp}, 269,758(18.62 \%)$ sequences having a length of $250 \mathrm{bp}, 157,147(10.85 \%)$ sequences having a length of $251 \mathrm{bp}, 145,130(10.02 \%)$ sequences having a length of $249 \mathrm{bp}$, and 113,720 (7.85\%) sequences having a length of $234 \mathrm{bp}$. For the vast majority of the sequence lengths, the number of sequences was $>1000$.

Species diversity and richness of fungal pathogens on grains from different ecological regions. In total, 1880 OTUs were produced from the sequencing of fungal pathogens on grains from 10 regions. When the calculated diversity indices were compared, the Chaol and ACE indices were similar to the OTUs. The highest Chaol and ACE index values were observed in samples from Dingxi City, and the lowest Chaol and ACE index values were observed in samples from Datong City. The highest values for the Shannon indices were observed in samples from Baicheng City, and the lowest values were observed in samples from Shannan Prefecture, Tibet (Table 2).

In total, 69 genera were detected on grain surface samples, with the dominant pathogens belonging to the genera Alternaria (5.4-64.0\%) and Davidiella (1.4-64.6\%). Alternaria was the dominant species in the Kelan (33.6\%), Dingxi (36.7\%), Datong (56.3\%), Chifeng (37.7\%), Jining (31.1\%), Hinggan League (64.0\%), Zhangjiakou (40.5\%), and Baicheng (28.8\%) regions. Davidiella was the dominant species in Shannan Prefecture (64.4\%) and Haidong Prefecture (53.9\%). Judging from the proportions, Alternaria was much more common than Davidiella in all regions (Fig. 1).

Hierarchical cluster analysis at the genus level revealed that 13 genera, including Alternaria, Pyrenophora, and Gibberella, belonged to one cluster, and 13 others, including Davidiella, Botrytis, and Bipolaris, belonged to 


\begin{tabular}{|l|l|l|l|l|}
\hline Ecological region & OTUs & Chaol estimator & ACE estimator & Shannon index \\
\hline Kelan County, Shanxi Province & 172 & 162.821 & 165.875 & 2.770 \\
\hline Dingxi City, Gansu Province & 188 & 201.954 & 201.729 & 2.121 \\
\hline Datong City, Shanxi Province & 156 & 138.167 & 150.132 & 1.928 \\
\hline Chifeng City, Inner Mongolia & 210 & 197.431 & 201.655 & 2.777 \\
\hline Jining City, Inner Mongolia & 180 & 176.888 & 181.924 & 2.373 \\
\hline Hinggan League, Inner Mongolia & 162 & 161.372 & 158.034 & 1.790 \\
\hline Zhangjiakou City, Hebei Province & 174 & 185.212 & 171.447 & 2.432 \\
\hline Baicheng City, Jilin Province & 182 & 189.288 & 174.731 & 3.131 \\
\hline Shannan Prefecture, Tibet & 152 & 151.611 & 165.347 & 1.779 \\
\hline Haidong Prefecture, Qinghai Province & 155 & 146.633 & 159.059 & 2.425 \\
\hline
\end{tabular}

Table 2. Diversity indices of fungal pathogens on grains of Bayou 13 from 10 ecological regions.
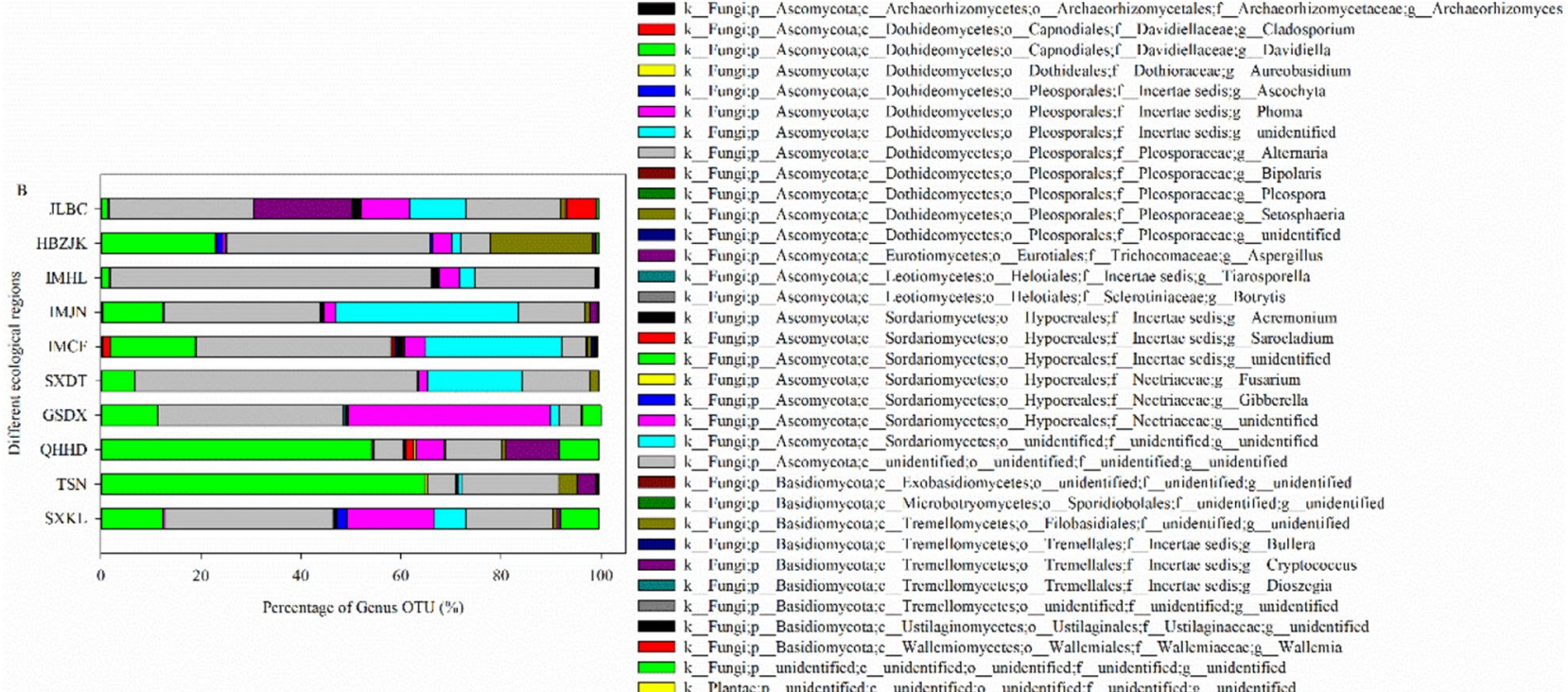

Figure 1. Genus-level taxonomic composition of fungal pathogens on grain surfaces of Bayou 13 from 10 ecological regions. SXKL, TSN, QHHD, SXDT, GSDX, IMCF, IMJN, IMHL, HBZJK, and JLBC indicate Kelan County in Shanxi Province; Shannan Prefecture in Tibet; Haidong Prefecture in Qinghai Province; Datong City in Shanxi Province; Dingxi City in Gansu Province; Chifeng City, Jining City, and Hinggan League in Inner Mongolia; Zhangjiakou City in Hebei Province; and Baicheng City in Jilin Province, respectively.

another cluster. When region-based clustering was performed, it was found that Haidong Prefecture formed a cluster of its own, and all other regions formed another cluster (Fig. 2).

Based on the richness of each species in the various samples, the correlations among species were calculated using the richness information at the genus level for the top 50 species. A correlation network consisting of significantly correlated species was constructed for the prediction of interactions among species. From Fig. 3, it can be seen that, with the exception of one negative correlation (i.e., competitive relationship), all other correlations between Davidiella and Alternaria were positive (i.e., collaborative relationships).

By eliminating these six indices, we found one significant single linear relationship between the percentage of Alternaria spp. $(y)$ and elevation (x): $y=53.272-0.013 x, R^{2}=0.568,\left(F_{1,9}=10.54, P<0.05\right)$, and there were significant differences in elevation $\left(t=-3.246, P_{x}<0.05\right)$; another relationship was found between the percentage of Davidiella spp. $(y)$ and elevation $(\mathrm{x}): y=-5.59+0.018 x, R^{2}=0.805,\left(F_{1,9}=33.064, P<0.05\right)$, and there were significant differences in elevation $\left(t=5.75, P_{x}<0.05\right)$.

Culture of fungal pathogens from grains from different ecological regions. Based on the information obtained on the fungal pathogen community (Supplementary Table S2, Supplementary Figure S2), the infestation ratio of all pathogens on the grains from Haidong Prefecture in Qinghai Province was significantly higher than that from Shannan Prefecture in Tibet and significantly lower than that in the other regions $(F=64.96, \mathrm{df}=29.9, P<0.05)$ (Fig. 4). Moreover, the infestation ratios of black pathogens from Shannan Prefecture in Tibet and Shannan and Haidong Prefectures were significantly lower than those from the other regions $(F=49.557, \mathrm{df}=29.9, P<0.05)$ (Fig. 4$)$. 


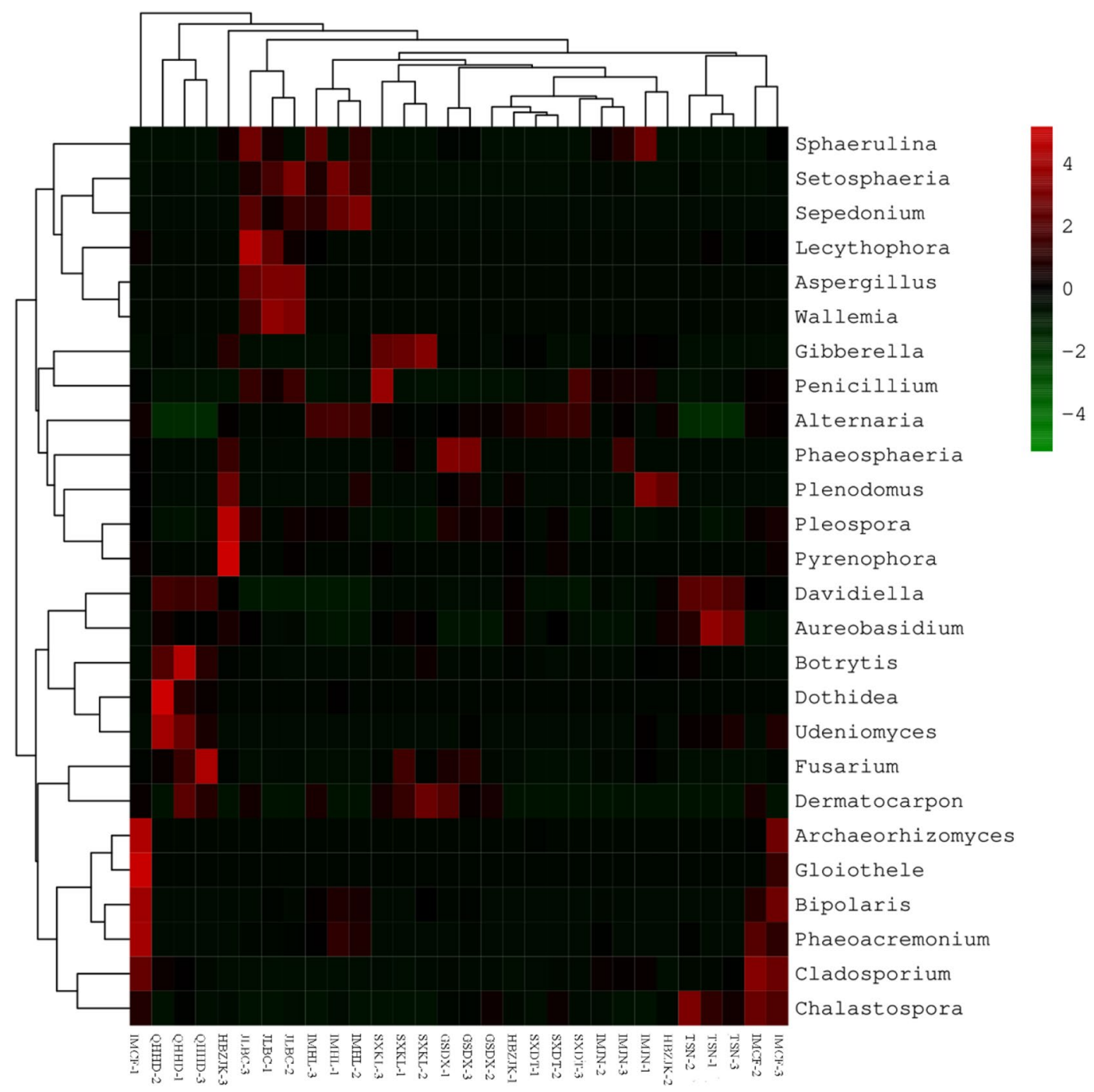

Figure 2. $16 \mathrm{~S}$ rDNA sequencing reveals the relationship and classification of fungal pathogens on the surfaces of Bayou 13 grains from 10 ecological regions at the genus level. The weighted UniFrac UPGMA tree is based on 13 fungal genera. The heat map shows the relative abundance of the 13 genera within each sample that were most abundant in the entire dataset. The abundance data were normalized by range-scaling each class to $\log _{2}$. SXKL, TSN, QHHD, SXDT, GSDX, IMCF, IMJN, IMHL, HBZJK and JLBC indicate Kelan County in Shanxi Province; Shannan Prefecture in Tibet; Haidong Prefecture in Qinghai Province; Datong City in Shanxi Province; Dingxi City in Gansu Province; Chifeng City, Jining City, and Hinggan League in Inner Mongolia; Zhangjiakou City in Hebei Province; and Baicheng City in Jilin Province, respectively.

Verification of SRD-causing fungal pathogens on grain surfaces. The black pathogen strains purified on the grain surfaces from the 10 ecological regions were identified as Alternaria spp. through sequencing analysis and morphological identification (Fig. 5). After the granules and glumes of the three groups had been cultured on PDA medium for 5 days, greenhouse experiments were performed, and the infestation ratios of granules $(F=142.855, \mathrm{df}=8.6, P<0.05)$ and glumes $(F=49.258, \mathrm{df}=8.6, P<0.05)$ in the control group were significantly higher than those in the normal growth group (untreated) and lower than those in the experimental group (Fig. 6). The black pathogen strains were again isolated from the granules and glumes of the experimental group. The isolates were observed to be consistent with the original isolates, thus fulfilling Koch's postulates.

\section{Discussion}

Through the investigation of the community structure of fungal pathogens on the surface of Bayou 13 oat grains from 10 ecological regions, our results showed that the fungal pathogens mainly belonged to 69 genera of Ascomycota and Basidiomycota, with the dominant pathogens belonging to Alternaria spp. and Davidiella spp. The same results were found in Lolium perenne and Trifolium repens ${ }^{32}$. These two fungal genera are widely distributed in different proportions in plants, aquatic ecosystems and soils ${ }^{33-35}$. Ascomycetes are more easily amplified than Basidiomycota with the ITS2 subsite ${ }^{36}$, while Davidiella was the dominant genus amplified with the ITS2 region ${ }^{37}$. Furthermore, we observed that these two genera exhibited a competitive relationship. A negative interaction 


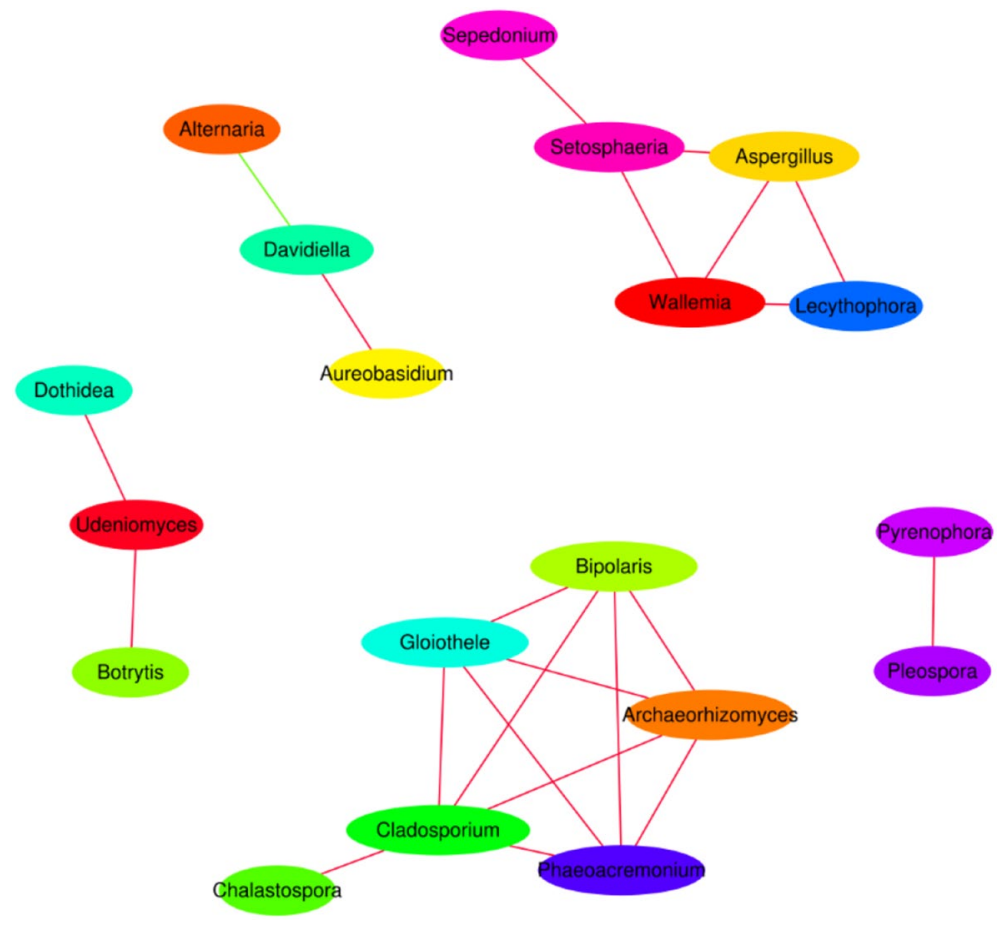

Figure 3. Network analyses at the genus level according to the abundance of fungal pathogens on the surface of Bayou 13 grains from 10 ecological regions. Network analyses of Spearman correlation coefficients reveal the cooccurrence patterns among genera. Different colors represent different genera. Edges (lines) between nodes are colored red for positive correlations between genera and green for negative correlations between genera.

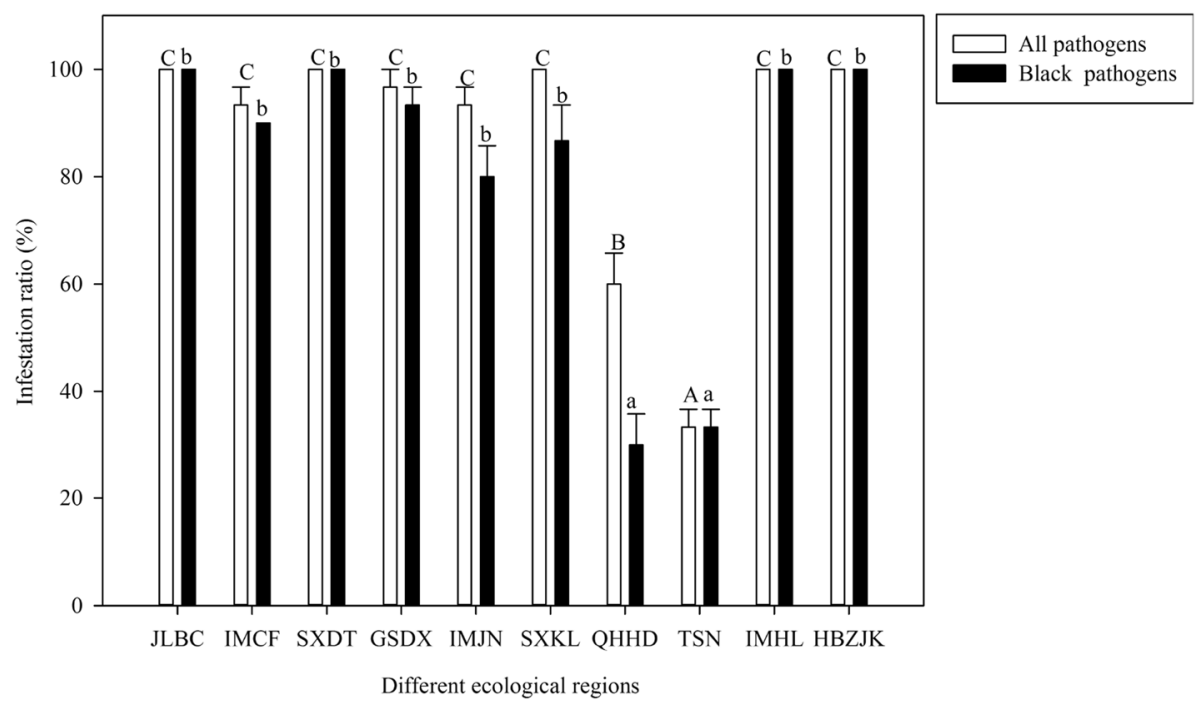

Figure 4. The comparison of infections by fungal pathogens after 5 days of culture on PDA on the surface of Bayou 13 grains from 10 ecological regions, China. The white and black columns represent the means for all pathogens and black pathogens, respectively, and the bars represent the SE. Different uppercase letters and lowercase letters above the columns indicate significant differences within the ten regions (least significant difference test, $P<0.05$ ) for all pathogens and black pathogens, respectively. SXKL, TSN, QHHD, SXDT, GSDX, IMCF, IMJN, IMHL, HBZJK and JLBC indicate Kelan County in Shanxi Province; Shannan Prefecture in Tibet; Haidong Prefecture in Qinghai Province; Datong City in Shanxi Province; Dingxi City in Gansu Province; Chifeng City, Jining City, and Hinggan League in Inner Mongolia; Zhangjiakou City in Hebei Province; and Baicheng City in Jilin Province, respectively. 
Alternaria sp. isolate TY172-10 small subunit ribosomal RNA gene, partial sequence; internal transcribed spacer 1, 5.8S ribosomal RNA gene, and internal transcribed spacer 2, complete sequence; and large subunit ribosomal RNA gene, partial sequence Sequence ID: MT089982.1 Length: 611 Number of Matches: 1 Range 1: 81 to 611

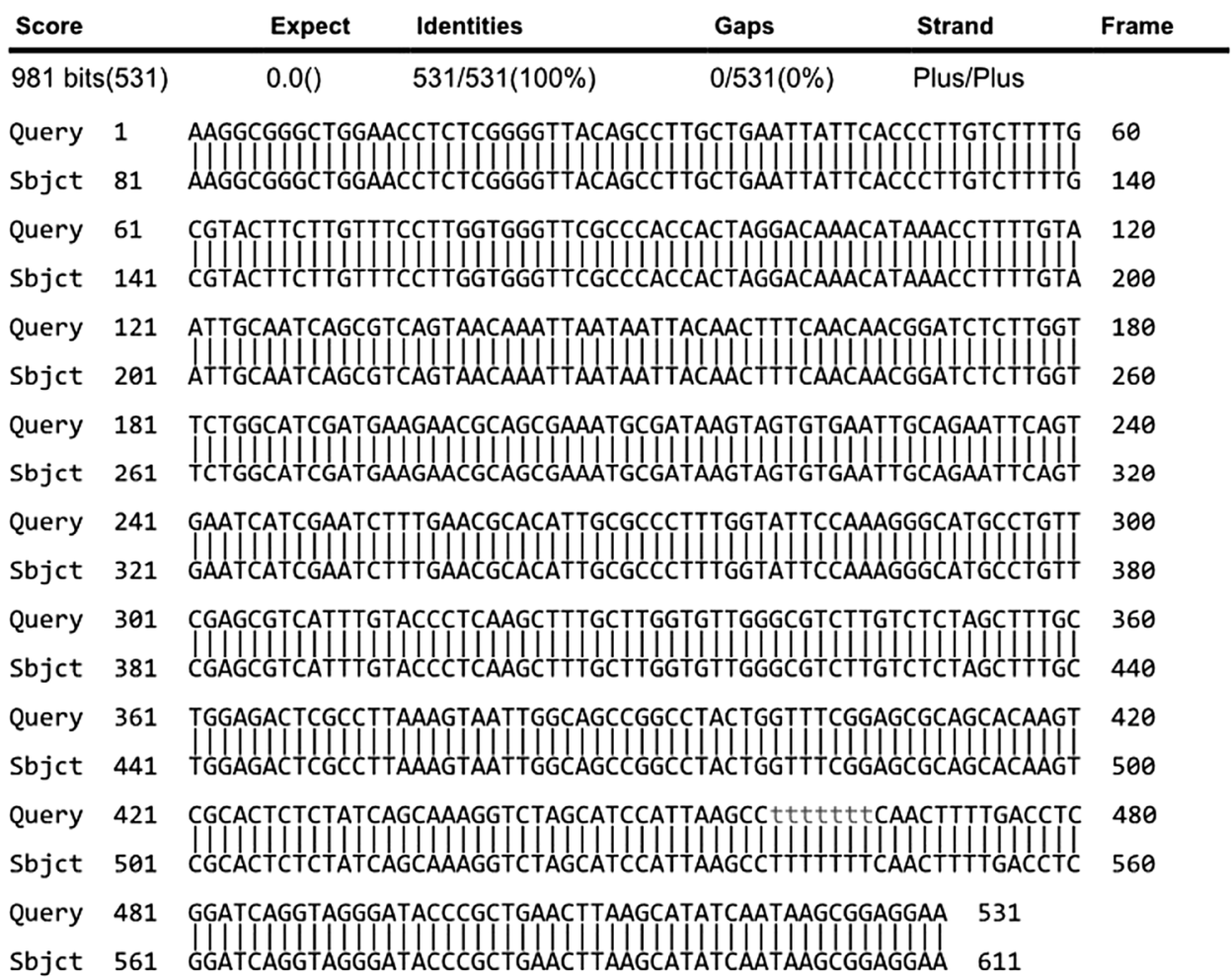

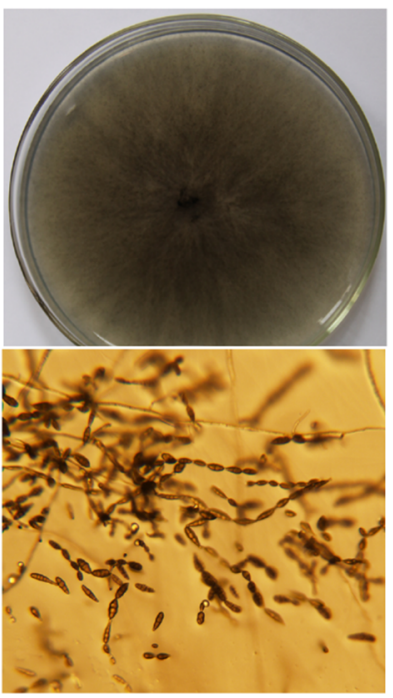

Figure 5. Molecular identification and BLAST comparison of Alternaria spp. on black spots of grains from three plates for each of the 10 ecological regions. A plate containing 10 mildewed grains of Bayou 13 cultured on PDA medium for 5 days.

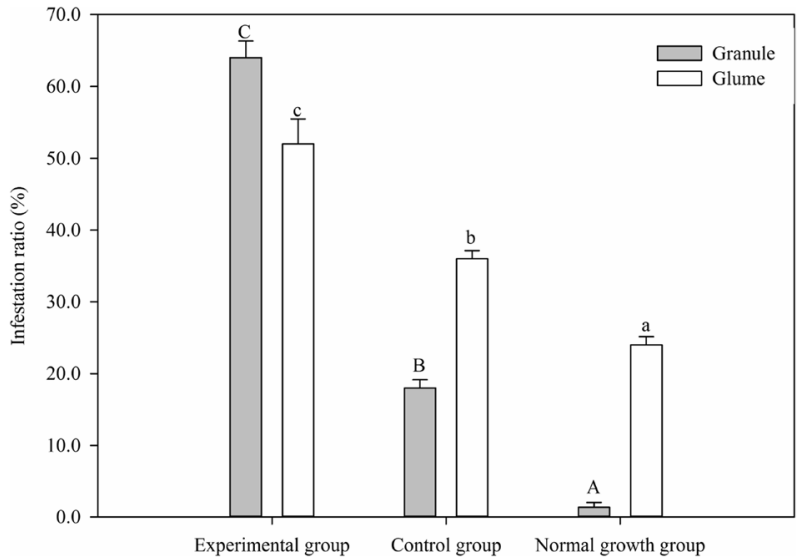

Figure 6. The comparison of infections by Alternaria spp. after 5 days of culture on PDA in the experimental group ( 2 weeks spraying with spore suspension of Alternaria), control group ( 2 weeks spraying with water containing $0.1 \%$ Tween-20), and normal growth group (untreated) for either glumes or grains of Bayou 13 from Kelan County in Shanxi Province, China. The gray and white columns represent the means for granules and glumes, respectively, and the bars represent the SE. Different uppercase and lowercase letters above the columns indicate significant differences within the three groups (least significant difference test, $P<0.05$ ) for granules and glumes, respectively. 
between Fusarium spp. and Alternaria spp. was found on the surface of wheat and barley grains of reduced quality $^{10,22}$. Fungal distribution is mainly affected by fungal interactions such as spatial competition ${ }^{38}$. This may explain why, except for Shannan Prefecture and Haidong Prefecture, the proportion of Ascomycota in the other eight regions was significantly higher than that of Basidiomycota, and Alternaria spp. were the dominant fungi in the eight regions. In addition to being proven with plate culture, fungal cooccurrence has been investigated by metagenomic approaches and network analysis ${ }^{39,40}$. We also found that Alternaria and Davidiella spp. were negatively and positively correlated with elevation, respectively. Elevational gradients exert a strong influence on the relationships among crops and their microbiota in alpine regions $\mathrm{s}^{41,42}$. This result thus indicated that elevation mainly affected the relative occurrence of Alternaria and Davidiella spp., presenting an inverse relationship with blackened surfaces of Chinese naked oat grains.

On the other hand, the infestation ratios on grains from Shannan Prefecture and Haidong Prefecture were significantly lower than those from the other eight regions. According to the Chinese Three Gradient Terrains ${ }^{43}$, Shannan Prefecture and Haidong Prefecture belong to the first terrain, Kelan, Dingxi, Datong, Jining, and Zhangjiakou belong to the second group, and Chifeng, Hinggan League, and Baicheng belong to the third group. Clearly, visible differences in black pigmentation were also found among the surface fungi of naked oat grains between the first terrain and the other terrains. This result thus indicated that SRD of naked oat characterized by black fungal discoloration mainly occurred in regions below $2000 \mathrm{~m}$ (elevation). Our previous reports showed that for grains of naked oat planted in Kelan, the infection level of Alternaria spp. on the black surface (38.7\%) was five times as much as that on the normal surface (7.6\%), while the infection level of Davidiella spp. on the black surface $(3.9 \%)$ was similar to that on the normal surface $(2.39 \%)^{27}$. Alternaria are dematiaceous fungi characterized by dark colonies ranging from gray to olive/brown ${ }^{44}$. Taking these results together, the black pathogen(s) causing SRD in eight of the regions examined may be Alternaria spp.

Further experimental results showed that the black pathogens cultured on PDA were Alternaria spp., which was consistent with the sequencing results; additionally, the greenhouse experiment results confirmed that Alternaria spp. was the cause of SRD of naked oat. Naked oat SRD differs from rice SRD ${ }^{17,18}$ in that it is associated with one pathogen. Oat leaf spot disease is only caused by Alternaria alternata ${ }^{45-47}$. Alternaria is one of the main mycotoxigenic fungal genera found in cereals worldwide ${ }^{48}$, causing diseases in over 400 host plants and postharvest spoilage of several crops $^{49,50}$. The prevalence of this fungus in cereals indicates a high disease incidence, with more than $90 \%$ of the grains affected in the field ${ }^{51}$ and more than $50 \%$ of the grains affected in the greenhouse experiment in our study. Reports of cereal diseases characterized by leaf blackening and blight associated with Alternaria are continually published ${ }^{16}$, and cereal grains are constantly affected by Alternaria spp. and their toxins ${ }^{51}$. Although Alternaria toxins are often neglected in grains, possibly due to the lack of severe economic losses directly caused by the genus, recent studies have shown that their frequency and ability to produce a wide range of toxins is significant ${ }^{10,16}$. With governments attaching great importance to the sustainable development of the environment and agriculture and people's concern for health, research and application of biological control are increasing. Microbial agents, botanical agents and resistance inducers are receiving increasing attention regarding their roles in the biocontrol of plant diseases caused by Alternaria ${ }^{52}$. Oat grains can be processed into many kinds of foods $s^{53}$. Thus, the finding that SRD of naked oat is caused by only Alternaria spp. presents an obvious advantage for the biological control of this disease.

\section{Conclusions}

SRD has become an emerging naked oat disease in China, as losses caused by the disease have been regularly increasing over recent years. The pathogens of SRD have been investigated in many regions of Tibet, Shanxi Province, Gansu Province, Inner Mongolia, Qinghai Province and Hebei Province, China. Using metagenomic analysis, molecular techniques and field validation, one causal agent was identified as Alternaria spp., and this disease mainly occurred at altitudes below $2000 \mathrm{~m}$. Our results can help improve the recognition, diagnosis, and management of this important disease. It is emphasized in this study that this disease is caused by a single pathogenic taxon, and further research into the application of antagonistic microbes against Alternaria spp. to prevent the occurrence of pre- and postharvest SRD of naked oat are required to ensure the production of certified oat materials.

\section{Materials and methods}

Plant material. Based on the Chinese oat and buckwheat industry, Bayou 13 plants have been grown for over five years in 10 different oat-producing regions (Datong City and Kelan County in Shanxi Province, Dingxi City in Gansu Province, Zhangjiakou City in Hebei Province, Baicheng City in Jilin Province, Shannan Prefecture in Tibet, Haidong Prefecture in Qinghai Province, and Chifeng City, Jining City, and Hinggan League in Inner Mongolia). The elevations, geographical coordinates, and meteorological data of the 10 regions are summarized in Supplementary Table S1. In Datong City, Dingxi City, Baicheng City, Chifeng City, and Hinggan League, Bayou 13 plants were sown in early April and harvested in early August. In Kelan County, Zhangjiakou City, Shannan Prefecture, Haidong Prefecture, and Jining City, Bayou 13 plants were sown in mid-late May and harvested in mid-September. In 2017, the seeds were sown in drills $3-5 \mathrm{~cm}$ deep, spaced ca. $25 \mathrm{~cm}$ apart and at an average rate of 450 seeds $\mathrm{m}^{-2}$ in these regions. Irrigation and fertilization were scheduled according to the oat requirements, soil storage capacity, and climate. The cropping system followed the guidelines of the National Oat and Buckwheat Industrial Technology System ${ }^{6}$. For each of the ten sites, we randomly selected three sampling plots; the plot dimensions were $10 \mathrm{~m} \times 5.0 \mathrm{~m}$, and each plot contained 20 rows. At the ripening stage of the Bayou 13 plants, $500 \mathrm{~g}$ of grains per plot for each region was collected by the Center for Agricultural Genetic Resources Research unit and stored in a polyethylene bag at $-80^{\circ} \mathrm{C}$. 
Collection of fungal pathogens on the grain surfaces and DNA extraction. The surfaces of oat grain samples were washed three times with phosphate-buffered saline (PBS), and the resultant pathogen-containing solutions were centrifuged at $15,000 \times g$ for $30 \mathrm{~s}$. After the supernatant was discarded, total pathogen genomic DNA samples were extracted using Fast DNA SPIN extraction kits (MP Biomedicals, Santa Ana, CA, USA) following the manufacturer's instructions and stored at $-20^{\circ} \mathrm{C}$ prior to further analysis. The quantity and quality of extracted DNA were measured using a NanoDrop ND-1000 spectrophotometer (Thermo Fisher Scientific, Waltham, MA, USA) and agarose gel electrophoresis, respectively.

16S rDNA amplicon sequencing. PCR amplification of the fungal ITS1 region was performed using the forward primer ITS5 (5'-GGAAGTAAAAGTCGTAACAAGG-3') and the reverse primer ITS2 (5'-GCTGCG TTCTTCATCGATGC-3'). Sample-specific 7-bp barcodes were incorporated into the primers for multiplex sequencing. PCR amplicons were purified with Agencourt AMPure Beads (Beckman Coulter, Indianapolis, IN, USA) and quantified using the PicoGreen dsDNA Assay Kit (Invitrogen, Carlsbad, CA, USA). After the individual quantification step, amplicons were pooled in equal amounts, and paired-end $2 \times 300 \mathrm{bp}$ sequencing was performed using the Illumina MiSeq platform with a MiSeq Reagent Kit v3 at Shanghai Personal Biotechnology Co., Ltd. (Shanghai, China).

Sequence analysis. The Quantitative Insights Into Microbial Ecology (QIIME, v1.8.0) bioinformatic pipeline was employed to process the sequencing data, as previously described ${ }^{54}$. Briefly, raw sequencing reads with exact matches to the barcodes were assigned to respective samples and identified as valid sequences. The lowquality sequences were filtered with previously reported criteria ${ }^{55,56}$. Paired-end reads were assembled using $\mathrm{FLASH}^{57}$. After chimera detection, the remaining high-quality sequences were clustered into operational taxonomic units (OTUs) at $97 \%$ sequence identity by UCLUST ${ }^{58}$. A representative sequence was selected from each OTU using default parameters. OTUs were taxonomically classified by BLAST, and the representative sequence set was searched against the Unite Database ${ }^{59}$ using the best hits ${ }^{60}$. An OTU table was also generated to record the abundance and taxonomy of each OTU in each sample. OTUs containing less than $0.001 \%$ of total sequences across all samples were discarded. To minimize the difference in sequencing depth across samples, an averaged, rounded rarefied OTU table was generated by averaging 100 evenly resampled OTU subsets under $90 \%$ of the minimum sequencing depth for further analysis.

Bioinformatics and statistical analysis. Sequence data analyses were mainly performed using QIIME and R packages (v3.2.0) ${ }^{61}$. OTU-level alpha diversity indices, such as the Chaol richness estimator, abundancebased coverage estimator (ACE) metric, and Shannon diversity index, were calculated using the OTU table in QIIME. Taxon abundances at the genus level were statistically compared among samples by Metastats ${ }^{62}$ and visualized as violin plots. Cooccurrence analysis was performed by calculating Spearman's rank correlations between predominant taxa. Correlations with $|\mathrm{RHO}|>0.6$ and $P<0.01$ were visualized as a cooccurrence network using Cytoscape ${ }^{63}$.

Culture offungal pathogens from surfaces of oat grains from different ecological regions. From the samples of each region, 30 oat grains from the initial $500 \mathrm{~g}$ of grains were randomly selected. A conventional tissue separation method was used for isolating and culturing samples ${ }^{64}$. After the germ had been removed from each grain using a sterilized blade, the grains were disinfected in 75\% ethanol for $30 \mathrm{~s}$, washed three times with sterile water, placed on sterile filter paper to absorb the excess water on the grain surfaces, and evenly arranged using sterile forceps on potato dextrose agar (PDA) medium (potato [Kunming, China], $200 \mathrm{gl}^{-1}$; glucose [Solarbio, Beijing, China], $20 \mathrm{~g} \mathrm{l}^{-1}$; agar, $15 \mathrm{~g} \mathrm{l}^{-1}$ ). For each ecological region, three PDA plates with 10 grains each were prepared, i.e., three parallel experiments were conducted. The loaded PDA plates were incubated in an upright position at $25^{\circ} \mathrm{C}$ without light for 5 days ${ }^{65}$. The number of black grains was counted, and the morphology of the pathogens on the surfaces of naked oat grains was preliminarily observed using an Olympus BX53 microscope (Olympus, Japan).

Identification of SRD-causing fungal pathogens on the surfaces of naked oat grains. According to the single spore isolation method ${ }^{66}$, single spores derived from all colonies around each grain from each region were selected from the culture medium. The purified strain was inoculated three to five times on new corn meal agar (CMA) medium (corn [Kunming, China], $20 \mathrm{~g} \mathrm{l}^{-1}$; agar [Biofroxx, Einhausen, Germany], $15 \mathrm{~g}$ $\mathrm{l}^{-1}$ ). Then, the purified strain was inoculated on a PDA plate and stored at $4{ }^{\circ} \mathrm{C}^{67}$. After dark culture at $25{ }^{\circ} \mathrm{C}$ for 1 week, DNA was extracted from the fungal isolates, and sequencing was conducted by Shanghai Personal Biotechnology Co., Ltd. (Shanghai, China). By sequencing comparison using BLAST in the NCBI database, Alternaria spp. was identified as the main pathogen.

Pathogenicity tests of Alternaria spp. on oat grains in the greenhouse. A pot cultivation trial using cultivar Bayou 13 plants collected from Kelan County was conducted in an environmentally controlled glass greenhouse at $25^{\circ} \mathrm{C}$ and under a 12:12 LD photoperiod from early November 2018 to late May 2019. This experiment included three groups with three replicates each: the normal growth group (untreated), control group (sprayed with water containing $0.1 \%$ Tween-20), and experimental group (sprayed with an Alternaria spore suspension). Approximately 20 normal seeds were sown in a porcelain pot $40 \mathrm{~cm}$ in diameter and $30 \mathrm{~cm}$ in height. For each group, six pots were placed in a $3 \mathrm{~m} \times 1.5 \mathrm{~m}$ plot as one repeat and arranged in two rows with interpot distances of $40 \mathrm{~cm}$; in total, 18 pots and three hundred and sixty seeds were used for each group. 
Each group was at least five meters apart. The preserved Alternaria was cultured on PDA at $25^{\circ} \mathrm{C}$ under a $12: 12$ LD photoperiod for 7 days. Subsequently, suspensions of conidia were prepared using sterile water containing $0.1 \%$ Tween-20, and the conidial suspensions were passed through two layers of a sterile cheesecloth to remove hyphal fragments ${ }^{68}$. Spore concentration was calculated using a hemocytometer and adjusted to $1 \times 10^{6}$ spores/ ml. During the maturation period, the experimental group was uniformly sprayed with the spore suspension, the control group was sprayed with sterile water containing $0.1 \%$ Tween-20, and the normal growth group was left untreated. Using a hand sprayer, $50 \mathrm{ml}$ of spore suspension or $0.1 \%$ Tween-20 solution for each batch of six pots was directly sprayed on the rachises; each rachis was then put in a transparent plastic bag to prevent drying ${ }^{69,70}$. Spraying was performed once every morning, noon, and night for 2 weeks during the maturity stage. From each plot, 50 granules and 50 glumes were randomly selected, surface disinfected using $75 \%$ ethanol for $30 \mathrm{~s}$, washed three times with sterile water, evenly arranged on CMA medium, and incubated at $25^{\circ} \mathrm{C}$. After 5 days, the number of black granules and glumes was recorded. The pathogens were isolated from the black areas of grains and glumes. The colony and conidial characteristics of the recovered pathogen were observed using an Olympus BX53 microscope (Olympus, Japan) and compared with those of the pathogen used for inoculation.

Statistical analysis. The infestation ratio was calculated using the following equation:

$$
\text { Infestation ratio }(\%)=\frac{\text { total number of infested grains or glumes }}{\text { total number of investigated grains or glumes }} \times 100
$$

Data collected from the infestation ratio of grains, granules, or glumes were used for one-way analysis of variance (Fisher's protected least significant difference), and normalized data were transformed using an arcsine square root function before analysis. Among ecological indices such as elevation, sunshine hours, temperature, rainfall, latitude and longitude from Supplementary Table S1, two models of key indices and two genera, Alternaria and Davidiella spp. were generated using stepwise backward selection ${ }^{71}$. All analyses were conducted in SPSS for Windows Version 16.0 (SPSS Inc., Chicago, Illinois, United States of America).

Received: 13 September 2020; Accepted: 18 December 2020

Published online: 13 January 2021

\section{References}

1. Loskutov, I. G. \& Rines, H. W. Avena. In Wild Crop Relatives: Genomic and Breeding Resources (ed. Kole, C.) 109-183 (Springer, Berlin, 2011).

2. Rodionova, N. A., Soldatov, V. N., Merezhko, V. E., Yarosh, N. P. \& Kobylyansky, V. D. Cultivated Flora: Oat (Kolos, 1994).

3. Loskutov, I. G. On evolutionary pathway of Avena species. Genet. Resour. Crop Evol. 55, 211-220 (2008).

4. Li, X. R. et al. A comparative analysis of nutrition components and functional active ingredients in Avena nuda and Avena sativa. Sci. Technol. Cereals Oils Foods 23, 50-54 (2015).

5. Warzecha, T., Zielinski, A., Skrzypek, E., Wojtowicz, T. \& Moś, M. Effect of mechanical damage on vigor, physiological parameters, and susceptibility of oat (Avena sativa) to Fusariumculmorum infection. Phytoparasitica 40, 29-36 (2012).

6. Ren, C. Z. et al. Establishment and application of high efficient breeding technology system of oat in China. J. Agric. Sci. Technol. 18, 1-6 (2016).

7. Liu, W. T. et al. Nutritional quality and correlation analysis of oat in different regions of China. Agric. Sci. Technol. Newsl. 12, 151-155274 (2019).

8. Tian, J. et al. Pathogenicity of Isaria fumosorosea to Bemisia tabaci, with some observations on the fungal infection process and host immune response. J. Invertebr. Pathol. 130, 147-153 (2015).

9. Ou, S. H. Rice Diseases 2nd edn. (C.A.B. International, Farnham House, Farnham Royal, Slough, 1987).

10. Kosiak, B., Torp, M., Skjerve, E. \& Andersen, B. Alternaria and fusarium in Norwegian grains of reduced quality-a matched pair sample study. Int. J. Food Microbiol. 93, 51-62 (2004).

11. Amatulli, M. T., Fanelli, F., Moretti, A., Mulé, G. \& Logrieco, A. F. Alternaria species and mycotoxins associated to black point of cereals. Mycotoxins 63, 39-46 (2013).

12. Banyal, D. K., Sood, V. K., Singh, A. \& Mawar, R. Integrated management of oat diseases in north-western himalaya. Range Manag. Agrofor. 37, 84-87 (2016).

13. Li, C. J., Chen, T. X., Zhao, G. Q. \& Nan, Z. B. Progress in research on diseases of Avena sativa. Acta Prataculturae Sin. 26, 203-222 (2017).

14. Tiwari, U. \& Cummins, E. Sensitivity analysis in predictive models for assessing the level of $\beta$-glucan in oats and barley cultivars using meta-models. Food Bioprocess Technol. 3(6), 935-945 (2010).

15. Gavrilova, O., Gannibal, P. \& Gagkaeva, T. Fusarium and Alternaria fungi in grain of oats grown in the north-western Russia regarding cultivar specificity. Sel'skokhozyaistvennaya Biol. 51, 111-118 (2016).

16. Tralamazza, S. M., Piacentini, K. C., Iwase, C. H. T. \& Rocha, L. O. Toxigenic Alternaria species: Impact in cereals worldwide. Curr. Opin. Food Sci. 23, 57-63 (2018).

17. Huang, S. W. et al. Rice spikelet rot disease in China-1. Characterization of fungi associated with the disease. Crop Prot. 30, 1-9 (2011).

18. Huang, S. W. et al. Rice spikelet rot disease in China-2. Pathogenicity tests, assessment of the importance of the disease, and preliminary evaluation of control options. Crop Prot. 30, 10-17 (2011).

19. Li, L. et al. Research progress of spikelet rot disease and bacterial panicle blight of rice. Chin. J. Rice Sci. 29, 215-222 (2015).

20. Sun, L. et al. Screening for strains of rice spikelet rot disease pathogenic fungus with high fumonisin production and strong pathogenicity. Chin. J. Rice Sci. 32, 610-616 (2018).

21. Sun, L. et al. Infection and colonization of pathogenic fungus fusarium proliferatum in rice spikelet rot disease. Rice Sci. 26, 60-68 (2019).

22. Andersen, B., Thrane, U., Svendsen, A. \& Rasmussen, I. A. Associated field mycobiota on malt barley. Can. J. Bot. 74, 854-858 (1996).

23. Dawood, M. Seed-borne fungi, especially pathogens of spring wheat. Acta. Mycol. 18, 83-112 (1982).

24. Kwaśna, H. \& Kosiak, B. Lewia avenicola sp. Nov. and its Alternaria anamorph from oat grain, with a key to the species of Lewia. Fungal Biol. 107, 371-376 (2003). 
25. Lahouar, A., Crespo-Sempere, A., Marín, S., Saïd, S. \& Sanchis, V. Toxigenic molds in Tunisian and Egyptian sorghum for human consumption. J. Stored Prod. Res. 63, 57-62 (2015).

26. Tralamazza, S. M., Bemvenuti, R. H., Zorzete, P., de Souza Garcia, F. \& Corrêa, B. Fungaldiversity and natural occurrence of deoxynivalenol and zearalenone in freshly harvested wheat grains from Brazil. Food Chem. 196, 445-456 (2016).

27. Liu, L. L. et al. Microbial flora on surface of mouldy oat grain and normal oat grain during harvest Season. J. Triticeae Crops 38, 372-378 (2018).

28. Gao, T. T. et al. Fungi community structure associated with Korean pine forests and the varying tendency with four forest land age. Nova Hedwigia 111, 391-415 (2020).

29. Mukhtar, H. et al. Climate and land cover shape the fungal community structure in topsoil. Sci. Total Environ. https://doi. org/10.1016/j.scitotenv.2020.141721 (2020).

30. Zeng, Q. C. et al. The local environment regulates biogeographic patterns of soil fungal communities on the Loess Plateau. CATENA 183, 104220. https://doi.org/10.1016/j.catena.2019.104220 (2019).

31. Zhou, Y. J. et al. A review on soil fungal community and its affecting factors in forest ecosystem. Ecol. Environ. Sci. 29, 1703-1712 (2020).

32. Lei, Y. H. et al. Detection and identification of seed-borne fungi isolated from imported grass seeds. Pratacultural. Sci. 33, 46-53 (2016).

33. Lim, Y. W. et al. Assessment of soil fungal communities using pyrosequencing. J. Microbiol. 48, 284-289 (2010).

34. Jones, E. B. G., Sakayaroj, J., Suetrong, S., Somrithipol, S. \& Pang, K. L. Classification of marine Ascomycota, anamorphic taxa and Basidiomycota. Fungal Divers. 35, 1-187 (2009).

35. Vandenkoornhuyse, P., Baldauf, S. L., Leyval, C., Straczek, J. \& Young, J. P. W. Extensive fungal diversity in plant roots. Science 295, 2051-2051 (2002).

36. Bellemain, E. et al. ITS as an environmental DNA barcode for fungi: An in silico approach reveals potential PCR biases. BMC Microbiol. 10, 189 (2010).

37. Anderson, I. C. \& Cairney, J. W. G. Diversity and ecology of soil fungal communities: Increased understanding through the application of molecular techniques. Environ. Microbiol. 6, 769-779 (2004).

38. Lacey, J. \& Magan, N. Fungi in cereal grains: Their occurrence and water and temperature relationships. In Cereal Grain Mycotoxins, Fungi and Quality in Drying and Storage (ed. Chelkowski, J.) 77-118 (Elsevier, New York, 1991).

39. Li, B. et al. Metagenomic and network analysis reveal wide distribution and co-occurrence of environmental antibiotic resistance genes. ISME J. 9, 2490-2502 (2015).

40. Toju, H., Tanabe, A. S. \& Sato, H. Network hubs in root-associated fungal metacommunities. Microbiome 6, 116 (2018).

41. Li, M. \& Yan, W. Effects of altitude on rhizosphere fungal community structure of Pinus tabulaeformis in Wula Mountain. Mycosystema 38, 1-15 (2019).

42. Xu, F., Yang, G. Q., Song, Y. L., Wang, J. M. \& Li, Y. H. Resistance to Fusarium head blight and deoxynivalenol accumulation in various tissues of wheat heads. Acta Phytopathol. Sin. 44, 651-657 (2014).

43. Jiang, J. \& Yang, X. Quantitative segmentation of the three gradient terrain of China based on DEM. Geomat. World 7, 8-13 (2009).

44. Kustrzeba-Wójcicka, I., Siwak, E., Terlecki, G., Wolańczyk-Mędrala, A. \& Mędrala, W. Alternaria alternata and its allergens: A comprehensive review. Clin. Rev. Allergy. Immunol. 47, 354-365 (2014).

45. Chen, H., Li, C. \& White, J. F. First report of Alternaria alternata causing leaf spot on oat (Avena sativa) in China. Plant Dis. https ://doi.org/10.1094/pdis-08-19-1692-pdn (2020).

46. Kim, Y. C. First report of leaf spots on oat caused by Alternaria alternata in South Korea. Plant Dis. https://doi.org/10.1094/PDIS08-20-1651-PDN (2020).

47. Raza, A. M. et al. Occurrence of leaf spot of oat caused by Alternaria alternata in Multan, Punjab, Pakistan. Plant Protect. 2, 83-86 (2018).

48. Deshpande, S. S. Handbook of Food Toxicology (Marcel Dekker Inc, New York, 2002),

49. Lee, H. B., Patriarca, A. \& Magan, N. Alternaria in food: Ecophysiology, mycotoxin production and toxicology. Mycobiology 43, 93-106 (2015).

50. Woudenberg, J. H. C. et al. Alternaria section Alternaria: Species, formae speciales or pathotypes?. Stud. Mycol. 82, 1-21 (2015).

51. Pinto, V. E. F. \& Patriarca, A. Alternaria species and their associated mycotoxins. In Mycotoxigenic Fungi (eds Moretti, A. \& Susca, A.) 13-32 (Human Press, New York, 2017).

52. Gao, F. \& Wu, Y. H. Progresses in the biocontrol of plant diseases caused by Alternaria. Plant Protect. 34, 1-6 (2018).

53. Liu, L. L. et al. Volatile profiles from traditional Chinese oat meal varied significantly from oat porridge and differed with cultivars and locations. J. Food Sci. 84, 2432-2440 (2019).

54. Caporaso, J. G. et al. QIIME allows analysis of high-throughput community sequencing data. Nat. Methods 7, 335-336 (2010).

55. Gill, S. R. et al. Metagenomic analysis of the human distal gut microbiome. Science 312, 1355-1359 (2006).

56. Chen, H. \& Jiang, W. Application of high-throughput sequencing in understanding human oral microbiome related with health and disease. Fron. Microbiol. 5, 6 (2014).

57. Magoč, T. \& Salzberg, S. L. FLASH: Fast length adjustment of short reads to improve genome assemblies. Bioinformatics 27, 2957-2963 (2011).

58. Edgar, R. C. Search and clustering orders of magnitude faster than BLAST. Bioinformatics 26, 2460-2461 (2010).

59. Kõljalg, U. et al. Towards a unified paradigm for sequence-based identification of fungi. Mol. Ecol. 22, 5271-5277 (2013).

60. Altschul, S. F. et al. Gapped BLAST and PSI-BLAST: A new generation of protein database search programs. Nucleic Acids Res. 25, 3389-3402 (1997).

61. R Core Team, R: A Language and Environment for Statistical Computing. R foundation for statistical computing, Vienna, Austria. https://www.R-project.org. (2015)

62. White, J. R., Nagarajan, N. \& Pop, M. Statistical methods for detecting differentially abundant features in clinical metagenomic samples. PLoS Comput. Biol. 5, e1000352. https://doi.org/10.1371/journal.pcbi.1000352 (2009).

63. Shannon, P. et al. Cytoscape: A software environment for integrated models of biomolecular interaction networks. Genome Res. 13, 2498-2504 (2003).

64. Fang, Z. D. Research Methods on Plant Pathology (China Agricultural Press, Beijing, 1998).

65. Meena, M., Swapnil, P. \& Upadhyay, R. S. Isolation, characterization and toxicological potential of Alternaria-mycotoxins (TeA, $\mathrm{AOH}$ and AME) in different Alternaria species from various regions of India. Sci. Rep. 7, 8777. https://doi.org/10.1038/s4159 8-017-09138-9 (2017).

66. Zhao, H., Huang, L., Xie, F. Q. \& Kang, Z. S. Culture study of Marssonina coronaria from diseased apple leaves. Mycosystema 28, 490-495 (2009).

67. Yin, H. et al. Identification, pathogenicity, and fungicide sensitivity of Ascochyta caulina (Teleomorph: Neocamarosporium calvescens) associated with black stem on quinoa in China. Plant Dis. https://doi.org/10.1094/PDIS-09-19-2042-RE (2020).

68. Li, L. et al. Induction of chlamydospore formation in fusarium by cyclic lipopeptide antibiotics from Bacillus subtilis C2. J. Chem. Ecol. 38, 966-974 (2012).

69. Mabbayad, M. O. \& Watson, A. K. Biological control of gooseweed (Sphenoclea zeylanica Gaertn.) with an Alternaria sp.. Crop Prot. 14, 429-433 (1995) 
70. Tülek, S. \& Dolar, F. S. Detection and identification of Alternaria species causing diseases of carrot in Ankara province, Turkey. Sci. Pap. Ser. B Hortic. 29, 263-268 (2015).

71. Kong, W. N. et al. Importance of preovipositional period of an oligophagous moth in predicting host suitability. J. Econ. Entomol. $113,222-229(2020)$.

\section{Acknowledgements}

We wish to thank the China Agriculture Research System (CARS-07-A-02) for its financial assistance. We would like to thank professor Siyu Hou, Shanxi agricultural university, China, for drawing these images by sequence alignment analysis and $\mathrm{R}$ software.

\section{Author contributions}

L.L. led the relevant project and designed the study. L.Z., Z.L., and J.Z. prepared the oat samples. M.M. collected the test data. L.L. and M.M. performed the data analyses. L.L. drafted the manuscript.

\section{Competing interests}

The authors declare no competing interests.

\section{Additional information}

Supplementary Information The online version contains supplementary material available at https://doi. org/10.1038/s41598-020-80273-6.

Correspondence and requests for materials should be addressed to L.L.

Reprints and permissions information is available at www.nature.com/reprints.

Publisher's note Springer Nature remains neutral with regard to jurisdictional claims in published maps and institutional affiliations.

(1) Open Access This article is licensed under a Creative Commons Attribution 4.0 International License, which permits use, sharing, adaptation, distribution and reproduction in any medium or format, as long as you give appropriate credit to the original author(s) and the source, provide a link to the Creative Commons licence, and indicate if changes were made. The images or other third party material in this article are included in the article's Creative Commons licence, unless indicated otherwise in a credit line to the material. If material is not included in the article's Creative Commons licence and your intended use is not permitted by statutory regulation or exceeds the permitted use, you will need to obtain permission directly from the copyright holder. To view a copy of this licence, visit http://creativecommons.org/licenses/by/4.0/.

(C) The Author(s) 2021 